\title{
Agreement of Cerebral State Index and Glasgow Coma Scale in Brain-Injured Patients
}

\author{
Mehrdad Mahdian ${ }^{1}$; Mohammad Reza Fazel ${ }^{1, *}$; Esmaeil Fakharian ${ }^{1}$; Hossein Akbari ${ }^{1}$; Soroush \\ Mahdian $^{2}$; Soheila Yadollahi ${ }^{3}$ \\ ${ }^{1}$ Trauma Research Center, Kashan University of Medical Sciences, Kashan, IR Iran \\ ${ }^{2}$ Student Research Committee, Arak University of Medical Sciences, Arak, IR Iran \\ ${ }^{3}$ Shahid-Beheshti Hospital, Kashan University of Medical Sciences, Kashan, IR Iran \\ ${ }^{*}$ Corresponding author: Mohammad Reza Fazel, Trauma Research Center, Kashan University of Medical Sciences, Kashan, IR Iran. Tel: +98-9132760380, Fax: +98-3615558883, \\ E-mail:drmfazel@yahoo.com
}

Received: November 1, 2013; Revised: December 17, 2013; Accepted: December 21, 2013

\begin{abstract}
Background: Variables derived from electroencephalogram like cerebral state index (CSI) have been used to monitor the anesthesia depth during general anesthesia. Observed evidences show such variables have also been used as a detector of brain death or outcome predictor in traumatic brain-injured (TBI) patients.

Objectives: The current study was designed to determine the correlation between Glasgow coma score (GCS) and CSI among TBI patients. Patients and Methods: In 60 brain-injured patients who did not need and receive sedatives, GCS and CSI were daily measured during the first ten days of their hospital stay. Correlation between GCS and CSI was studied using the Pearson's correlation test. The Gamma agreement coefficient was also calculated between the two variables for the first day of hospitalization.

Results: A significant correlation coefficient of 0.611-0.796 was observed between CSI and GCS in a ten-day period of the study $(\mathrm{P}<0.001)$. Gamma agreement coefficient was $0.79(\mathrm{P}<0.001)$ for CSI and GCS for the first day of hospitalization. An increased daily correlation was observed in both CSI and GCS values. However, this increase was less significant in CSI compared with the GCS.

Conclusions: A statistically significant correlation and agreement was found between GCS and CSI in the brain-injured patients and GCS was also found to be more consistent and reliable compared with CSI.
\end{abstract}

Keywords:Cerebrum; Glasgow Coma Scale; Brain Injury

\section{Background}

Traumatic brain injury (TBI) is one of the major causes of post-injuries mortality and disability, worldwide (1). TBI is characterized by the loss of consciousness and Glasgow coma scale (GCS) is used for routine assessment of the patients' consciousness level. In non-traumatic unconsciousness like during anesthesia, variables derived from electroencephalogram (EEG) like bispectral index (BIS) and cerebral state index (CSI) have been widely used to monitor the depth of anesthesia objectively and quantitatively (2). Among these indices further studies have been undertaken based on BIS (3-5). Many investigators have tried to broaden the monitoring use of BIS for TBI patients $(6,7)$ and among those many studies found a significant correlation between BIS and GCS (8-11) and some did not (12). The CSI value which was introduced as a new instrument for measuring hypnotic depth in 2004, is passively derived from EEG and demonstrates a dimensionless score from 0 to 100 (13-16). Unlike BIS, few studies have been performed on CSI monitoring in brain-injured patients. This study was conducted to determine the cor- relation and agreement between GCS and CSI in unsedated traumatic brain- injured patients.

\section{Objectives}

The purpose of this study was to assess the degree of agreement and correlation between GCS as a subjective and CSI as an objective method to evaluate the consciousness in TBI patients.

\section{Patients and Methods}

This prospective observational study was performed after approval and informed consent in patients with mild (GCS 13-15), moderate (GCS 9-12) and severe (GCS 3-8) head injury. All patients had been admitted to the neurosurgical ICU of Shahid-Beheshti Hospital, Kashan University of Medical Sciences, Iran, between December 2011 and March 2012. Demographic characteristics, mechanism of head injury, GCS, computed tomography scan, and neurological examination at the time of admission were recorded. Patients demanding sedatives were excluded from the study. Since some of the patients un- 
derwent intracranial surgical operation, to eliminate the effect of anesthesia on consciousness indices, GCS and CSI were measured three hours after recovery from general anesthesia in these cases. Respiratory and metabolic disorders were considered as exclusion criteria, due to their potential effects on GCS, and patients with such problems did not enter the study. CSI was measured after the ICU admission and afterwards on a daily basis for the next nine days. CSI was measured using CSI monitor (CSI ${ }^{\mathrm{TM}}$ Danmeter, Odese, Denmark). To measure CSI, the patient's skin was prepared by swapping with alcohol and wiping. Standard electrocardiogram electrodes (SKIN$\mathrm{TACT}^{\circledR}$, Leonard Long $\mathrm{GmbH}$, Innsbruk, Austria) were then positioned as recommended by the manufacturer. After controlling of electrode impedance, the numerical value of CSI, ranging 0-100, was recorded for each patient by a nurse who was blinded to the study. Patients' neurological status was assessed using the GCS and recorded, at the moment of CSI measuring.

\subsection{Statistical Analysis}

Correlation between GCS and CSI was calculated using Pearson's correlation test. To eliminate the effect of surgical operation and patients' death on the study, adjustments regarding these factors were performed and partial correlation was calculated in addition to the crude correlation. Gamma agreement coefficient was also calculated between two variables for the first day of hospi- talization. Mean and standard deviations for CSI and GCS values in brain injured patients in different days were also compared using t-test.

\section{Results}

A total of 60 brain-injured patients (53 male and seven female cases) aged (mean \pm SD) $33.4 \pm 17.1$ years were included in the study. The injury mechanism was road traffic accident in 49 cases, falling in nine and assault in two patients. Fourteen patients had mild injury, 13 had moderate and 33 had severe injuries. The majority of cases were admitted to the ICU due to subdural hematoma and during the course of the study 26 cases underwent surgical operation due to intracranial mass lesion and 17 patients (28.3\%) expired due to their condition deterioration (Table 1). Ten sets of data were collected for each patient. An increased daily correlation was observed in both CSI and GCS values. However, this increase was less significant for CSI than that of the GCS. A significant correlation coefficient (crude correlation) of 0.611-0.796 between CSI and GCS was observed in the ten-day study. A significant partial correlation was also noted between the two indices regarding adjustment of surgical operation and death during the study period (Table 2). The highest correlation coefficient between GCS and CSI in all the patients was observed on the sixth day of hospitalization $(\mathrm{r}=0.796, \mathrm{P}<0.001)$ (Figure 1). Gamma agreement coefficient for CSI and GCS was $0.79(\mathrm{P}<0.001)$ for the first day of hospitalization.

\begin{tabular}{lccc}
\hline Table 1. Patients' Outcomes Regarding Their CT Scan-Based Diagnoses ${ }^{\text {a }}$ & & & \\
\hline Outcome Diagnosis & Death & Transfer to Post-ICU Ward & Sum \\
\hline Subdural hematoma & $8(42.1)$ & $11(57.9)$ & 19 \\
Epidural hematoma & $2(11.8)$ & $15(88.2)$ & 17 \\
Cerebral contusion & $2(22.2)$ & $7(77.8)$ & 9 \\
Diffuse axonal injury & $4(40)$ & $6(60)$ & 10 \\
Intracranial Hemorrhage & $1(20)$ & $4(80)$ & 5 \\
Sum & $17(28.3)$ & $43(71.7)$ & 60 \\
\hline
\end{tabular}

a All data are expressed as No(\%).

Table 2. Correlation Between GCS and CSI in Different Days of Hospitalization (Including Crude and Adjusted Correlation Regarding Death and Surgical Operation)

\begin{tabular}{lccc}
\hline Correlation, Days & $\begin{array}{c}\text { Crude Correlation } \\
\text { Partial Correlation Adjusted } \\
\text { for Death }\end{array}$ & $\begin{array}{c}\text { Partial Correlation Adjusted for Surgical } \\
\text { Operation }\end{array}$ & 0.479 \\
\hline $\mathbf{2}$ & 0.648 & 0.473 & 0.731 \\
$\mathbf{3}$ & 0.661 & 0.628 & 0.787 \\
$\mathbf{4}$ & 0.723 & 0.723 & 0.772 \\
$\mathbf{5}$ & 0.739 & 0.721 & 0.695 \\
$\mathbf{6}$ & 0.726 & 0.619 & 0.79 \\
$\mathbf{7}$ & 0.796 & 0.68 & 0.73 \\
$\mathbf{8}$ & 0.725 & 0.612 & 0.646 \\
$\mathbf{9}$ & 0.662 & 0.529 & 0.6 \\
\hline $\mathbf{1 0}$ & 0.611 & 0.457 & 0.68 \\
\hline
\end{tabular}




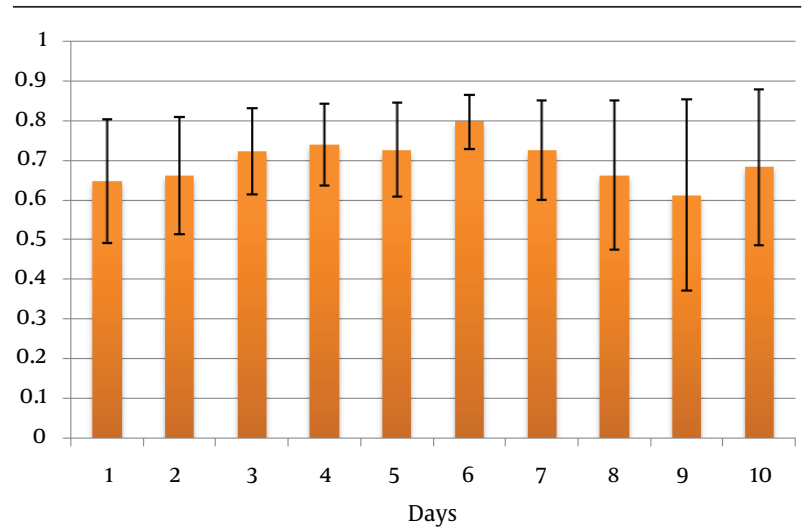

Figure 1. Correlation Coefficient and 95\% Confidence Interval of GCS and CSI During Hospitalization

\section{Discussion}

The present study showed that there is a statistically significant correlation and agreement between GCS and CSI in patients with traumatic brain injury. Although we have found a correlation between GCS and CSI in patients during all days of hospitalization, interestingly, we found GCS was more consistent than the CSI.

Basically, cerebral state index has been developed for monitoring the depth of anesthesia during operations. Its predecessor, BIS, has been also used for monitoring of consciousness during the management of both traumatic and non-traumatic coma $(6,17)$. The CSI, like BIS, is a quantitative EEG derived measure index that provides a dimensionless score from 0 to 100 to characterize the level of hypnosis. Although EEG monitoring is the gold standard for intraoperative monitoring of cerebral ischemia but common monitoring of EEG is inconvenient and obtaining signals without artifacts may be difficult in the operating room and intensive care settings (6). Therefore, it is preferable to use simple tools to measure BIS or CSI. Unlike BIS that was used in many studies to evaluate the consciousness state and diagnosis of brain death in comatose patients $(6,7,11,18-21)$, limited clinical studies have been conducted on the CSI in this area. Of course there are series of studies showing values of CSI and BIS, which are not significantly different (22-24). However, as previously mentioned, BIS measurement has recently been used for patients with traumatic brain injuries with severity of the injury $(6,7,10,20)$. The findings of the present study are consistent with previous observations and suggested that CSI values also correlate with severity of brain injury. These findings also corroborate the ideas of Ming XU et al. (2011), suggested that CSI monitoring presumably is a reliable objective technique to predict consciousness level of patients following elective intracranial surgeries (25). However, the findings of the current study does not support the published study by Nasraway et al. (2002) (12) who compared BIS with the sedation- agitation scale (SAS) as a subjective tool for monitoring of consciousness in critically ill patients. They concluded that the correlation between SAS and BIS scores was less than optimum and unpredictable in a different group of ICU patients. This inconsistency with our results may be due to the nature of the two subjective tools. They used SAS while the index used in the present study was GCS. In addition, this study was performed on the brain-injured patients while they studied on a heterogeneous group of patients. Finally, a significant correlation and agreement was found between GCS and CSI in brain-injured patients. So, CSI can be used as an adjunct to GCS to evaluate the consciousness in these patients.

\section{Acknowledgements}

The authors gratefully would like to thank Kashan University of Medical Sciences for the support. The authors also would like to thank Mr. Amir Motamed Nejad, Ms. Fatemeh Gholami and the staff of the intensive care unit of Kashan Shahid-Beheshti Hospital for their assistance in data gathering.

\section{Authors' Contribution}

Mehrdad Mahdian was in charge of idea, design and implementation of the study, Mohammad Reza Fazel supervised it, Esmaeil Fakharian took responsibility of the result interpretation, Hossein Akbari did the statistical analysis, Soroush Mahdian revised the study draft and Soheila Yadollahi was in charge of the data collection.

\section{Financial Disclosure}

The authors declare that there is no conflict of interest.

\section{Funding/Support}

This study was supported by Deputy of Research, Kashan University of Medical Sciences (Grant no: 8914).

\section{References}

1. Utomo WK, Gabbe BJ, Simpson PM, Cameron PA. Predictors of in-hospital mortality and 6-month functional outcomes in older adults after moderate to severe traumatic brain injury. Injury. 2009;40(9):973-7.

2. Wang Q, Xu M, Lei YN, Wang GN, Zhou JX. Use of cerebral state index monitoring to detect purposeful movement in unsedated brain-injured patients. J Int Med Res. 2009;37(3):689-96.

3. Bresil P, Nielsson MS, Malver LP, Kraemer K, Schjorring O, Dethlefsen $\mathrm{C}$, et al. Impact of bispectral index for monitoring propofol remifentanil anaesthesia. A randomised clinical trial. Acta Anaesthesiol Scand. 2013;57(8):978-87.

4. Krieger A, Panoskaltsis N, Mantalaris A, Georgiadis M, Pistikopoulos E. Modelling and analysis of individualized pharmacokinetics and pharmacodynamics for volatile anaesthesia. IEEE Trans Biomed Eng. 2013.

5. Cheung YM, Scoones GP, Hoeks SE, Stolker RJ, Weber F. Evaluation of the aepEX monitor of hypnotic depth in pediatric patients receiving propofol-remifentanil anesthesia. Paediatr Anaesth. 2013;23(10):891-7.

6. Paul DB, Umamaheswara Rao GS. Correlation of Bispectral Index with Glasgow Coma Score in mild and moderate head injuries. $J$ 
Clin Monit Comput. 2006;20(6):399-404.

7. Fabregas N, Gambus PL, Valero R, Carrero EJ, Salvador L, Zavala E, et al. Can bispectral index monitoring predict recovery of consciousness in patients with severe brain injury? Anesthesiology. 2004;101(1):43-51.

8. Simmons LE, Riker RR, Prato BS, Fraser GL. Assessing sedation during intensive care unit mechanical ventilation with the Bispectral Index and the Sedation-Agitation Scale. Crit Care Med. 1999;27(8):1499-504.

9. Riker RR, Fraser GL, Simmons LE, Wilkins ML. Validating the Sedation-Agitation Scale with the Bispectral Index and Visual Analog Scale in adult ICU patients after cardiac surgery. Intensive Care Med. 2001;27(5):853-8.

10. Deogaonkar A, Gupta R, DeGeorgia M, Sabharwal V, Gopakumaran B, Schubert A, et al. Bispectral Index monitoring correlates with sedation scales in brain-injured patients. Crit Care Med. 2004;32(12):2403-6.

11. Gilbert TT, Wagner MR, Halukurike V, Paz HL, Garland A. Use of bispectral electroencephalogram monitoring to assess neurologic status in unsedated, critically ill patients. Crit Care Med. 2001;29(10):1996-2000.

12. Nasraway SS, Jr., Wu EC, Kelleher RM, Yasuda CM, Donnelly AM. How reliable is the Bispectral Index in critically ill patients? A prospective, comparative, single-blinded observer study. Crit Care Med. 2002;30(7):1483-7.

13. Anderson RE, Barr G, Jakobsson JG. Cerebral state index during anaesthetic induction: a comparative study with propofol or nitrous oxide. Acta Anaesthesiol Scand. 2005;49(6):750-3.

14. Hoymork SC, Hval K, Jensen EW, Raeder J. Can the cerebral state monitor replace the bispectral index in monitoring hypnotic effect during propofol/remifentanil anaesthesia? Acta Anaesthesiol Scand. 2007;51(2):210-6.

15. Anderson RE, Sartipy U, Jakobsson JG. Use of conventional ECG electrodes for depth of anaesthesia monitoring using the ce- rebral state index: a clinical study in day surgery. Br J Anaesth. 2007;98(5):645-8.

16. Anderson RE, Jakobsson JG. Cerebral state index: comparison between pairwise registrations from the left and the right sides of the brain. BrJAnaesth. 2006;97(3):347-50.

17. Fraser GL, Riker RR. Bispectral index monitoring in the intensive care unit provides more signal than noise. Pharmacotherapy. 2005;25(5 Pt 2):19S-27S.

18. Dunham CM, Katradis DA, Williams MD. The bispectral index, a useful adjunct for the timely diagnosis of brain death in the comatose trauma patient. Am J Surg. 2009;198(6):846-51.

19. Schnakers C, Ledoux D, Majerus S, Damas P, Damas F, Lambermont B, et al. Diagnostic and prognostic use of bispectral index in coma, vegetative state and related disorders. Brain Inj. 2008;22(12):926-31.

20. Ebtehaj M, Yaqubi S, Seddighi AS, Seddighi A, Yazdi Z. Correlation between BIS and GCS in patients suffering from head injury. Ir J Med Sci. 2012;181(1):77-80.

21. Vivien B, Paqueron X, Le Cosquer P, Langeron O, Coriat P, Riou B Detection of brain death onset using the bispectral index in severely comatose patients. Intensive Care Med. 2002;28(4):419-25.

22. Cortinez LI, Delfino AE, Fuentes R, Munoz HR. Performance of the cerebral state index during increasing levels of propofol anesthesia: a comparison with the bispectral index. Anesth Analg. 2007;104(3):605-10.

23. Nishiyama T, Komatsu K. Cerebral state index versus bispectral index during propofol-fentanyl-nitrous oxide anesthesia. J Anesth. 2010;24(3):380-5.

24. Nishiyama T. Cerebral state index vs. bispectral index during sevoflurane-nitrous oxide anaesthesia. Eur I Anaesthesiol. 2009;26(8):638-42.

25. Xu M, Lei YN, Zhou JX. Use of cerebral state index to predict longterm unconsciousness in patients after elective craniotomy with delay recovery. BMC Neurol. 2011;11:15. 